\title{
Article \\ Perinatal Gram-Positive Bacteria Exposure Elicits Distinct Cytokine Responses In Vitro
}

\author{
Edith Reuschel ${ }^{1, *(D)}$, Martina Toelge ${ }^{2,+}$, Sebastian Haeusler ${ }^{1}$, Ludwig Deml ${ }^{2, \ddagger}$, Birgit Seelbach-Goebel ${ }^{1}$ \\ and Maria Emilia Solano ${ }^{3, *}$
}

1 University Department of Obstetrics and Gynecology At The Hospital St. Hedwig of The Order of St. John, University of Regensburg, 93049 Regensburg, Germany; Sebastian.Haeusler@barmherzige-regensburg.de (S.H.); Seelbach.B@web.de (B.S.-G.)

2 Institute of Clinical Microbiology and Hygiene, University Hospital Regensburg, 93053 Regensburg, Germany; Martina.Toelge@klinik.uni-regensburg.de (M.T.);

Ludwig.Deml@lophius.com (L.D.)

3 Department of Obstetrics and Feto-Maternal Medicine, University Medical Center Hamburg-Eppendorf, 20246 Hamburg, Germany

* Correspondence: Edith.reuschel@barmherzige-regensburg.de (E.R.); E.Solano@uke.de (M.E.S.)

+ Current Address: MicroBIOMix GmbH, 93053 Regensburg, Germany.

‡ Current Address: Lophius Biosciences GmbH, 93053 Regensburg, Germany.

Citation: Reuschel, E.; Toelge, M.; Haeusler, S.; Deml, L.; SeelbachGoebel, B.; Solano, M.E. Perinatal Gram-Positive Bacteria Exposure Elicits Distinct Cytokine Responses In Vitro. Int. J. Mol. Sci. 2021, 22, 332. https://doi.org/ 10.3390/ijms22010332

Received: 15 December 2020 Accepted: 21 December 2020 Published: 30 December 2020

Publisher's Note: MDPI stays neutral with regard to jurisdictional clai$\mathrm{ms}$ in published maps and institutional affiliations.

Copyright: (C) 2020 by the authors. Licensee MDPI, Basel, Switzerland. This article is an open access article distributed under the terms and conditions of the Creative Commons Attribution (CC BY) license (https:// creativecommons.org/licenses/by/ $4.0 /)$.
Abstract: During pregnancy, infections caused by the gram-positive bacteria Enterococcus faecalis (E. faecalis), Streptococcus agalacticae (S. agalacticae), and Staphylococcus aureus (S. aureus) are major reasons for preterm labor, neonatal prematurity, meningitis, or sepsis. Here, we propose cytokine responses to bacterial infections by the immature perinatal immune system as central players in the pathogenesis of preterm birth and neonatal sepsis. We aimed to close the gap in knowledge about such cytokine responses by stimulating freshly isolated umbilical blood mononuclear cells (UBMC) with lysates of E. faecalis, S. agalacticae, and S. aureus collected from pregnant women in preterm labor. Bacterial lysates and, principally, S. aureus and S. agalacticae distinctly triggered most of the eleven inflammatory, anti-inflammatory, $\mathrm{TH}_{1} / \mathrm{TH}_{2}$ cytokines, and chemokines quantified in UBMC culture media. Chemokines depicted the most robust induction. Among them, MIP-1 $\beta$ was further enhanced in UBMC from female compered to male newborn infants. Due to its stability and high levels, we investigated the diagnostic value of IL-8. IL-8 was critically upregulated in cord blood of preterm neonates suffering from infections compared to gestational age-matched controls. Our results provide novel clues about perinatal immunity, underscoring a potential value of IL-8 for the timely detection of infections and suggesting that MIP-1 $\beta$ constitutes an early determinant of sex-specific immunity, which may contribute, e.g., to male's vulnerability to preterm birth.

Keywords: preterm birth; gram-positive bacterial infection; neonatal immunity; sex-specific immunity

\section{Introduction}

Prematurity due to preterm birth is a main cause of short-term (e.g., respiratory distress and intraventricular hemorrhage) or long-term neonatal morbidities [1] and even death. Worldwide, 15 million babies per year are born due to preterm labor [2] arising from uterine contractility prior to 37 weeks of gestation in human [3]. This early onset of labor has been associated to multiple factors, among which intrauterine inflammation and ascending genital tract infections play a leading role [4]. It is typically considered that intrauterine infections induce the release of potent inflammatory mediators, such as cytokines and chemokines, which promote leukocyte recruitment and inflammation and ultimately result in premature uterine contractions and birth [5]. Intriguingly, these inflammatory reactions are mediated not only by maternal uterine leukocytes but also by fetal immune cells that migrate to the uterus and are highly reactive towards environmental signals $[6,7]$. 
High frequencies of pathogenic gram-negative and -positive bacteria were identified in vaginal and cervical swabs of women with impeding preterm labor [8]. The most ubiquitous species was the gram-negative Escherichia coli, which was present in $90 \%$ of the women investigated. Gram negative bacteria, often of nosocomial origin and known to cause dangerous infections, have shown concerning increases in antimicrobial resistance over the last decades [9]. Remarkably, the gram-positive Enterococcus faecalis (E. faecalis), Group B Streptococcus (GBS), and Staphylococcus aureus (S. agalactiae) were also highly prevalent, being respectively detected in $64 \%, 24 \%$, and $10 \%$ of women with impeding preterm birth [8]. Although these three gram-positive bacteria species are often present in the vaginal microbiome [10], they can also mediate opportunistic perinatal infections, chorioamnionitis, and/or neonatal sepsis, causing a substantial disease burden to Intensive Care Units [11].

In fact, an increase in the incidence of enterococcal bacteremia frequently of nosocomial origin has been reported, with E. faecalis being the most prominent strain [12-14]. E. faecalis does not account for a large number of neonatal sepsis cases, but it can be responsible for infections of the urogenital tract and endocarditis both in the mother and the neonate $[15,16]$. In turn, the gram-positive GBS Streptococcus agalactiae (S. agalacticae), harmless in pregnant women, can also cause severe infections in neonates. Despite intrapartum antibiotic prophylaxis, S. agalactiae is still the pathogen that most frequently causes early-onset sepsis within the first week of life and invasive GBS infection continues to be the leading cause of pneumonia and meningitis in neonates [15,16]. Finally, S. aureus is an emerging cause of chorioamnionitis and preterm rupture of membranes. Infants born from mothers positive for these bacteria present increased odds of S. aureus colonization [17], which is a risk factor for subsequent $S$. aureus infection. Such infections are among the most common causes of late-onset sepsis, for example, in very-low birth weight neonates $[18,19]$.

Taken together, these vaginal pathogenic bacteria not only pose a serious threat for the baby to be born too early but also may lead to congenital infections in the uterus, at birth, or after a latency period $[20,21]$. This may occur due to, e.g., aspiration or ingestion of bacteria in the amniotic fluid or during passage through the birth canal [22]. Due to immaturity of the neonatal immune system, such an infection can lead to sepsis [23]. Neonatal sepsis is a systemic condition that elicits hemodynamic changes, tissue damage, and distinct clinical features. As some of these symptoms can be provoked by potent inflammatory cytokines, neonatal sepsis has also been referred to as systemic inflammatory response syndrome [22] Despite progress in perinatal care, the incidence of prenatal and neonatal sepsis remains approximately two per 1000 live births, constituting a significant hardship at these early life stages. Further improvements are still required for its timely diagnosis, as studies have shown that 60 percent of lethal neonatal sepsis failed to be identified prior to death [23,24]. In this context, forthcoming challenges appear to surface in obstetric and neonatal care with regards to perinatal infections. Indeed, the continuous increase in antimicrobial resistance requires not only early detection of infections but also availability of antimicrobials with higher efficacy, i.e., by using superior host materials, to control them [25].

Based on the evidence reported, it is tempting to hypothesize that the cytokine responses by perinatal leukocytes to bacterial infections are a fundamental element in the pathogenesis of preterm birth and neonatal sepsis. Here, we postulate that bacteria present in the vagina of women undergoing preterm labor induce distinct inflammatory responses. Given that perinatal E. coli infection has already been the subject of thorough investigations [26], the aim of our present study was to characterize in depth the cytokine responses specific to the three clinically relevant vaginally occurring gram-positive bacteria frequently found in pregnant women with preterm labor, namely S. agalacticae, E. faecalis, and S. aureus. We hypothesize that these bacteria evoke distinct cytokine and chemokine responses that not only pose critical clinical challenges but also may hold diagnostic value.

To test this hypothesis, we first established an in vitro system of freshly prepared umbilical cord blood mononuclear cells (UBMC) from uncomplicated term deliveries, which we stimulated with the lysates of the mentioned gram-positive vaginal bacteria. 
The release of relevant preselected cytokines and chemokines upon bacterial stimulation was determined using the Luminex technology. The existence of sex-specific patterns in cytokine secretion was assessed. Based on these findings, IL-8 was proposed as a stable and reliable diagnostic marker for perinatal infections and was tested in cord blood of preterm neonates.

\section{Results}

2.1. Bacterial Lysates Trigger the Secretion of Cytokines and Chemokines by Umbilical Cord Blood Mononuclear Cells

Here, we established an in vitro setting in which UBMC freshly isolated from healthy neonates born at term were incubated for $36 \mathrm{~h}$ with the lysates from the selected grampositive vaginally occurring bacteria found in vaginal swabs of pregnant women with impending preterm birth: S. agalacticae, E. faecalis, and S. aureus (Figure 1A).
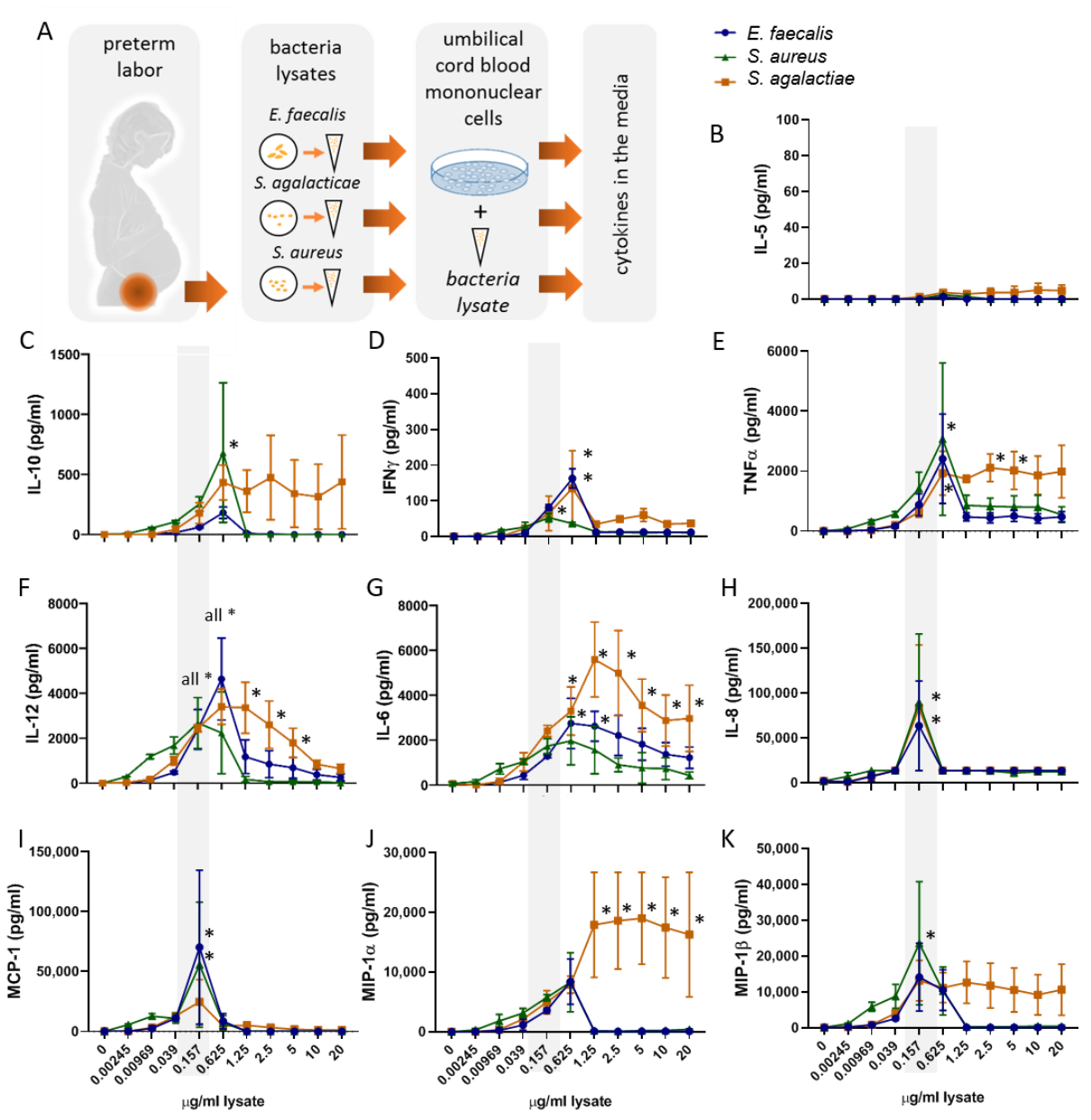

Figure 1. Experimental setup and optimization of umbilical blood mononuclear cells and bacteria lysate stimulation conditions: in our experimental design (A) vaginal and cervical bacteria samples from women with impeding preterm labor were collected. E. faecalis, S. agalacticae, and S. aureus were isolated and cultured to produce bacteria lysates. Umbilical blood mononuclear cells (UBMC) from ten term-born infants were stimulated in triplicates for $36 \mathrm{~h}$ with or without the respective bacterial lysates. The levels of preselected cytokines and chemokines were determined in the supernatants. (B-K) Increasing concentrations of bacteria extract $(0.00245-20 \mu \mathrm{g} / \mathrm{mL}$ lysate) were tested for the induction of ten cytokines (IL-5, IL-10, IFN $\gamma$, TNF $\alpha$, IL-12, IL-6, IL-8, MCP-1, MIP-1 $\alpha$, und MIP-1 $\beta)$, detected using luminex technology. With exception of IL-5 (B), the bacteria lysates significantly induced cytokine secretion $(\mathbf{C}-\mathbf{K})($ two-way ANOVA $p<0.05)$. ${ }^{*} p<0.05$ in Dunnett's multiple comparisons test. Concentrations of $0.157 \mu \mathrm{g}$ lysate $/ \mathrm{mL}$ (grey shadow) were selected for further experiments. IL-12 refers to IL12p40/70. The three bacteria are depicted as follows: E. faecalis (blue circles), S. agalacticae (orange squares), and $S$. aureus (green triangles). 
We first aimed to identify the optimal bacterial lysate concentrations among the ten dilutions tested as well as to select the cytokines of relevance in the context of the studied bacteria (Figure 1). Here, the cumulative release of cytokines upon $36 \mathrm{~h}$ of bacterial lysates stimulation was analyzed by Luminex in the conditioned culture media of UBMC. As shown in Figure 1C-K, a bimodal dose-dependent induction of most of the pro-and anti-inflammatory, and $\mathrm{TH}_{1}$-type cytokines and chemokines investigated was observed. Specifically, all cytokines rose between 0.0039 and $0.625 \mu \mathrm{g} / \mathrm{mL}$ of the bacterial lysate, whilst higher concentrations resulted in either stabilization or reduction of cytokine values. We selected the concentration of $0.157 \mu \mathrm{g} / \mathrm{mL}$ of the gram-positive lysate as optimal to detect changes in the cytokines and chemokines of interest. By selecting this concentration, we ensured that the immune response remained operational and below toxicity or saturation levels, which may otherwise prevent the assessment of differences between the effects of the three bacteria lysates. In this regard, the release of TNF $\alpha$ and IL-12 in the culture media was also compared between samples stimulated for 4 or $36 \mathrm{~h}$. As expected, at $4 \mathrm{~h}$, the secretion of the pro-inflammatory cytokine $\mathrm{TNF} \alpha$, associated to initiation of the immune response, was already comparatively high, whereas the levels of the cytokine IL-12, involved in promoting a $\mathrm{TH}_{1}$-type response, remained close to detection levels, mirroring the expected delay of adaptive immune responses (Figure S1A,B). After 36 h of bacteria stimulation, the cytokine levels were detectable and still increased, indicating that this is an adequate time to evaluate both innate and adaptive cytokine responses in our in vitro system.

Of note, bacterial lysates did not have a significant effect on the levels of IL-5 (Figure 1H) and TGF $\beta$ (Figure S2A) (two-way ANOVA analysis, factor: lysate concentration $p>0.1$ ). Additional determinations confirmed that these culture conditions do not result in significant IL-5 secretion (Figure S2B). For these reasons, IL-5 and TGF- $B$ were not included in further analyses.

\subsection{The Bacterial Lysates Elicit Distinct Patterns of Cytokines Responses}

In a next step, ten UBMC samples were stimulated with $0.157 \mu \mathrm{g} / \mathrm{mL}$ of bacterial lysate or with culture media (negative control) for $36 \mathrm{~h}$. Relevant information about the UBMC donors is summarized in Table 1. Levels of secreted anti-inflammatory (IL-10), inflammatory or $\mathrm{TH}_{1}$-cytokines (IL-6, $\mathrm{TNF} \alpha, \mathrm{IL}-12$, and IFN $\gamma$ ), as well as inflammatory chemokines (IL-8, MIP-1 $\alpha$, MCP-1, and MIP-1 $\beta$ ) were measured by Luminex.

Table 1. Descriptive information about the UBMC donors.

\begin{tabular}{|c|c|c|c|c|c|c|}
\hline $\begin{array}{l}\text { Subject } \\
\text { Number }\end{array}$ & $\begin{array}{c}\text { Maternal } \\
\text { Age (Years) }\end{array}$ & Parity & $\begin{array}{l}\text { Gestational Age } \\
\text { (Weeks + Days) }\end{array}$ & $\begin{array}{c}\text { Maternal BMI } \\
\text { Before Pregnancy }\end{array}$ & $\begin{array}{l}\text { Neonatal Birth } \\
\text { Weight (g) }\end{array}$ & Neonatalsex \\
\hline 1 & 31 & 6 & $40+3$ & 25.9 & 3810 & Male \\
\hline 2 & 29 & 2 & $41+0$ & 24.1 & 3540 & Female \\
\hline 3 & 33 & 1 & $39+4$ & 31.9 & 4150 & Female \\
\hline 4 & 29 & 2 & $40+6$ & 30.8 & 3740 & Male \\
\hline 5 & 27 & 1 & $40+1$ & 22.1 & 3150 & Female \\
\hline 6 & 34 & 1 & $40+5$ & 35.0 & 3300 & Male \\
\hline 7 & 25 & 2 & $38+5$ & 32.4 & 3800 & Male \\
\hline 8 & 27 & 1 & $39+4$ & 22.5 & 3620 & Male \\
\hline 9 & 30 & 2 & $37+1$ & 21.5 & 2830 & Female \\
\hline 10 & 27 & 1 & $37+0$ & 22.9 & 2570 & Female \\
\hline Median & 29 & 1.5 & $39+3$ & 25.0 & 3580 & \\
\hline Range & $25-31$ & $1-6$ & $37-41$ & $21.5-35.0$ & 2570-4150 & \\
\hline
\end{tabular}


As expected, compared to the negative controls, the three prepared bacterial lysates (S. agalacticae, E. faecalis, and S. aureus) potently induced the secretion of all nine cytokines and chemokines included in this analysis (Figure 2A). The qualitative evaluation of the heatmap for all cytokines according to the bacterial lysate employed suggested a generally stronger cytokine response in the case of $S$. aureus than the other bacteria. We confirmed this differential response of the UBMC to the bacterial lysates by comparing the levels of each cytokine or chemokine using Friedman test for paired samples. In particular, significantly higher levels of IL-10, TNF $\alpha$, IL-12, IL-6, MIP-1 $\beta$, and MIP- $1 \alpha$ were detected in cultures stimulated with $S$. aureus than in those with $E$. faecalis lysates (Figure 2B-J). In turn, $S$. agalactiae evoked intermediate responses, with higher levels of IL-10, IL-6, IL-8, and MIP-1 $\beta$ than E. faecalis and lower levels of TNF $\alpha$ than S. aureus. In contrast, an opposite trend was observed in the case of MCP-1, which presented higher levels in E. faecalis than in the other bacteria lysate stimulation (Figure 2H). Finally, no significant differences were found among the minor secretion of IFN $\gamma$ triggered by the three bacterial lysates (Figure 2C).

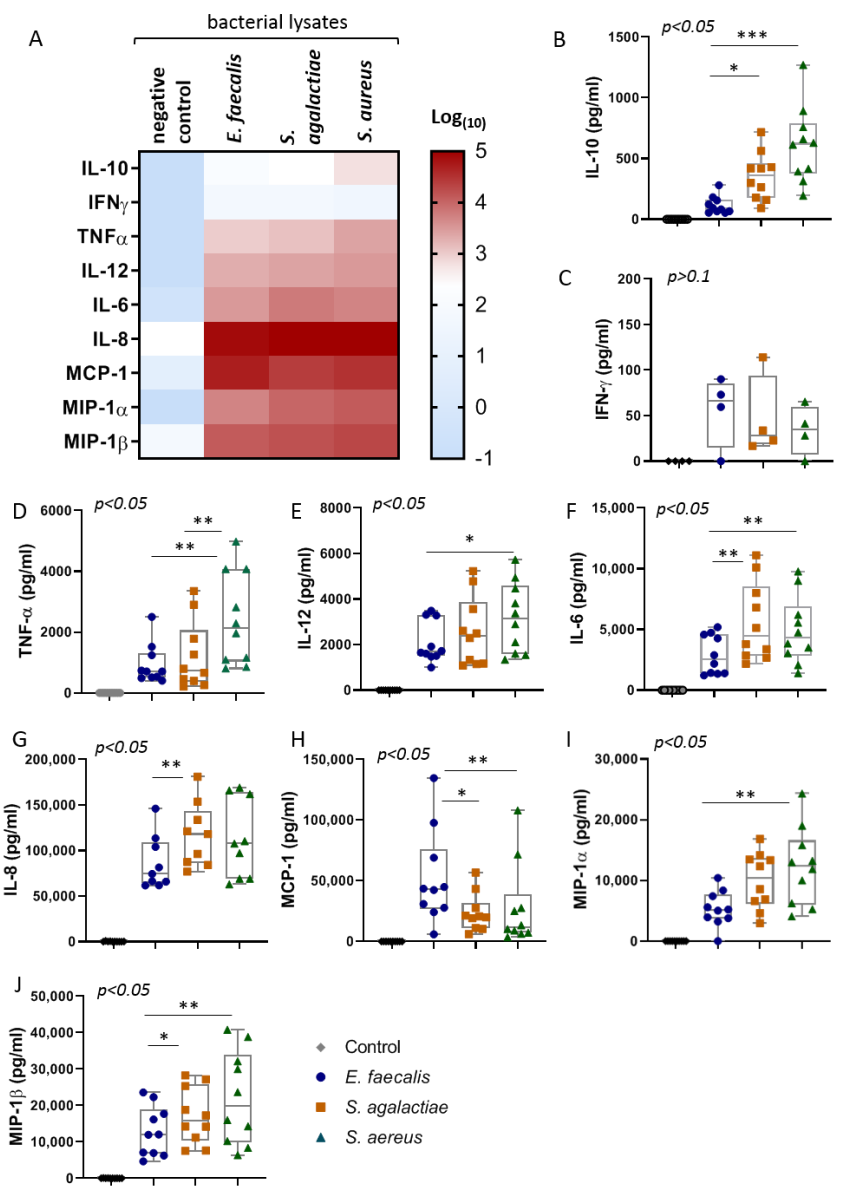

Figure 2. The bacterial lysates elicit distinct patterns of cytokines responses. (A) The heatmap depicts the median value for the cytokines and chemokines indicated in the left (rows), according to the bacterial stimuli (columns). The color scale is defined on the right. As the median values are reported in logarithmic (10) scale, values of $0 \mathrm{pg} / \mathrm{mL}$ were replaced by $0.1 \mathrm{pg} / \mathrm{mL}$. (B-J) Boxplots for each one of the cytokines and chemokines analyzed upon stimulation with or without lysates from E. faecalis (circles), S. agalacticae (squares), S. aureus (triangles), and controls (diamonds). Overall statistical differences in the cytokine levels between the three bacteria lysate stimulations were compared using the nonparametric Friedman Test ( $p$ values are presented in the top left of B-J). $p$ values for the posterior multiple comparisons are depicted as * $p<0.05 ;{ }^{* *} p<0.001$; ${ }^{* * *} p<0.0001$ (Dunn's Test correction). $n=10$. IL-12 refers to IL12p40/70. Boxplots represent the median, minimum, and maximal values, whilst the dots depict the individual values. 
Noteworthy, in all stimulation conditions, IL-8 was the cytokine that reached the highest concentrations in the culture media. These findings underscore that, among the detected cytokines, IL-8 may represent the most sensitive biomarker for cord blood diagnosis of perinatal infections with these three bacterial species.

\subsection{Umbilical Blood Mononuclear Cells from Female Infants Respond More Pronouncedly to Bacterial Lysates than Those from Male Infants}

In order to dissect possible factors that influence the immune response to the respective bacteria, we next considered the cytokine response to the bacterial lysates according to the sex of the infants who donated the UBMC samples. In the cultures used as negative controls, no differences in the basal cytokine levels were observed between females and males (Figure 3A). The qualitative assessment of the heatmap patterns (Figure 3A) indicated that samples derived from female infants presented a widespread more robust response to bacteria lysates than UBMC derived from male infants. In particular, the strongest sex dimorphism was observed in the levels of the chemokine MIP-1 $\beta$ in response to the three bacteria lysates (Figure 3I), whereas a similar but nonsignificant trend was observed in the cases of MCP-1 and MIP- $1 \alpha$ (Figure 3G-H).
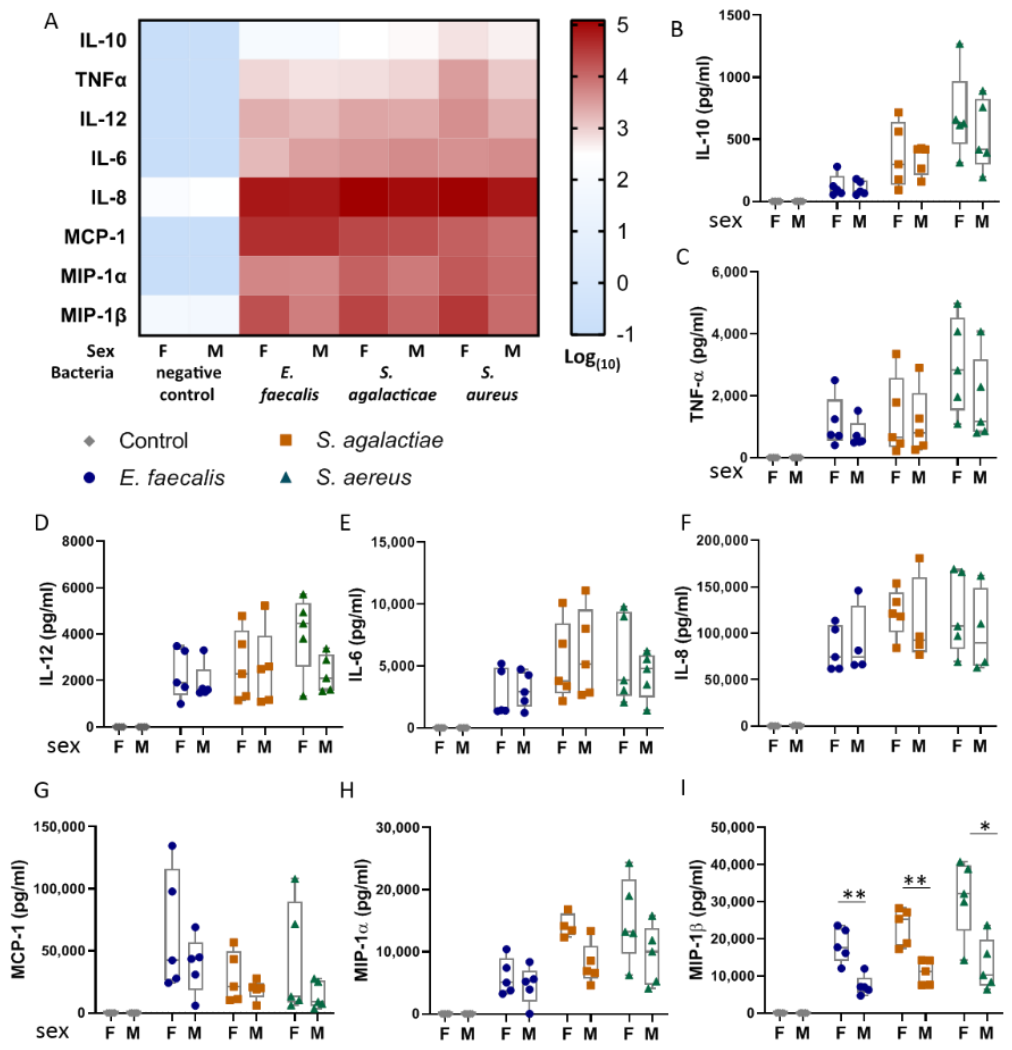

Figure 3. The sex of the infant determines the intensity of MIP-1 $\beta$ responses to bacterial lysates. (A) The heatmap presents in each row the median value for the cytokine and chemokines depicted in the left according to the treatment and the sex of the infants from whom the samples were collected (columns). The values are presented in logarithmic (10) scale as shown in the right. (B-I) The individual cytokines and chemokines detected upon stimulation with or without lysates from $E$. faecalis (circles), S. agalacticae (squares), S. aureus (triangles), and controls (diamonds) are presented in boxplots. For each bacteria lysate, the levels of the respective cytokines were compared between cultures of UBMC from female (F) and male (M) donors: ${ }^{*} p<0.05 ;{ }^{* *} p<0.001$. MannWhitney U Test. Boxplots represent the median, minimum, and maximal, whilst the dots depict the individual values.

Of note, the sex of the sample donors had no influence on the levels of IL-8, suggesting that this chemokine constitutes a stable marker to screen for neonates suffering from 
infections at birth, independent not only of the infecting bacteria species but also of the sex of the neonate.

\subsection{IL-8 Levels in Cord Blood of Preterm Newborn Infants is a Stable Indicator of Perinatal Infections}

In a next step, we investigated whether IL-8 was also detectable in infants suffering from infections in vivo. In this analysis, we collected cord-blood samples from newborn infants that were born preterm suspected to be due to infections. Cord blood collected from gestational age-matched infants born due to noninfectious pregnancy pathologies served as control (Table S2). As depicted in Figure 4, we observed that the levels of IL-8 dramatically increased in the cord blood of neonates that were confirmed to suffer from bacterial infections, compared to those not affected by infections. These results suggest that IL-8 may constitute a useful marker to rapidly detect neonates affected by infections at birth.

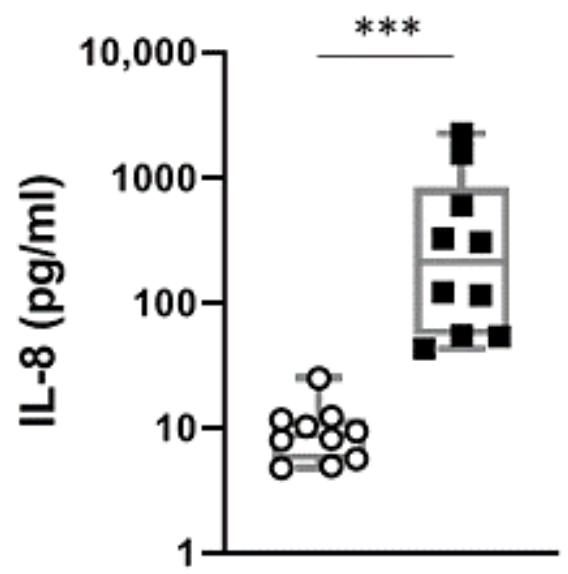

\section{Non-infected - Infected}

Figure 4. IL-8 was significantly increased in preterm newborns that suffered from infections. The levels of IL-8 were determined in cord blood of preterm born infants that suffered (back squares) or not (white circles) from infections. The results are presented in boxplots indicating the median, percentiles, and maximum and minimum values, whilst the dots depict the individual values. ${ }^{* * *} p<$ 0.0001, Mann-Whitney U Test. $n=10$.

\section{Discussion}

In the presence of perinatal infections, the triggered cytokine milieu is critically involved in the progress and outcome of the immune response. We could observe here that freshly isolated UBMC responded specifically to in vitro stimulation by lysates of three common vaginal gram-positive bacteria species. This involved a substantial upregulation of the chemokines IL- 8 and MCP-1, as well as MIP- $1 \alpha$ and MIP- $1 \beta$ by the bacterial lysates. In the context of intraamniotic infection, these chemokines establish a gradient that favors the migration of neutrophils and other effector leukocytes from the maternal or fetal circulation into the chorioamniotic membranes or umbilical cord, respectively [27].

Strikingly, MIP-1 $\beta$ secretion presented a marked sex-specific pattern, characterized by reduced levels in the case of male UBMC donors. This appeared as a solid phenomena, which manifested with the three bacteria studied. In line with our observations, the male sex of the offspring is a well-known risk factor for preterm birth as well as for neonatal complications [28]. This includes the higher vulnerability of males to severe neonatal infections and sepsis [29] in contrast to a sex bias towards more efficient immune responses in females, that endures throughout life [30]. Clearly, it would be interesting to learn if this sexual dimorphism is swiftly detectable in vivo. However, as shown by our data and others, the diverse bacteria and times postinfection [31] are factors that cause significant variability in MIP- $1 \beta$ and that cannot readily be controlled for in human infections, likely hindering the recognition of sex differences in MIP-1 $\beta$ secretion in the 
context of perinatal infections. Hence, besides the current ex vivo experiments, further clues about the importance of MIP- $1 \beta$ in sex-specific responses may be gained using mouse models of perinatal infection, e.g., with $S$. aureus. Indeed, contrasting reports appear in the literature comparing sex-specific expression of chemokines in the context of host response or inflammatory tissue damage $[30,32,33]$, which could be explained by the disparity in the progress of the immune responses analyzed. For example, MIP- $1 \beta$ was increased by LPS in the blood [34] and brain [35] of female but not of male mice. However, the characterization of sex-specific responses to gram-positive bacteria remains to date elusive and merits further investigations. Intriguingly, due to its potent chemoattractant capacity on Treg cells [36], MIP-1 $\beta$-increased secretion by cells from females might be involved in a more efficient resolution of the inflammatory response and the prevention of neonatal sepsis compared to male neonates. Hence, we propose that the reported robust upregulation of the chemokines MIP-1 $\beta$ at early stages of the inflammatory response in females may enhance a more rapid immune response than in males and may provide efficient host defense, consequently restraining propagation of the infection to reach a posterior sepsis state. In this manner, the studied chemotactic signals may constitute key early events driving sex specificity in the pathogenesis of infection-associated preterm labor and perinatal infections.

Although it is generally considered that sexual dimorphism in immunity responds chiefly to female or male sex hormones, it may also be influenced by genetic or immune traits inherent to each sex [33,37]. Our reported sex-specific differences in MIP-1 $\beta$ secretion in the minimalist design of our in vitro system can only stem from intrinsic differences between the UBMC responses in females and males. For example, leukocytes from females have been reported to express greater density of toll-like receptors, critically involved in pathogen recognition [30], which could be associated to the induction of stronger responses. Although critical mechanisms underlying sex differences in acute inflammation remain unknown, our observations could be also related to subtle changes in the immune function of the UBMC, which is the subject of our current studies.

In comparison to the other investigated chemokines, IL-8 presented no sex-dimorphism and exhibited the most robust release throughout our experiments. The low variability and high levels reached by IL-8 suggested that it could be readily detected in cord blood from infants suffering from perinatal infections. Previously, neonatal serum IL-8 in combination with clinical anamnesis has been proposed as a helpful biomarker for early diagnosis of neonatal sepsis [38]. Indeed, we could confirm exacerbated IL-8 levels already in cord blood of preterm neonates suffering from intrauterine infections, which was unambiguously increased compared to non-infected neonates. The high levels reached by IL-8 could be an advantage to establish clinically applicable threshold values, indicating that IL-8 could hold high relevance as a diagnostic biomarker for early identification of infections in the neonate. Noteworthy, IL-6 and IL-10 have also been recommended as indicators of neonatal sepsis [39] and increased levels of IL- 6 and TNF $\alpha$ in vaginal secretions of women with preterm premature rupture of membranes were good predictors of fetal inflammatory response syndrome [40]. Hence, further studies are required to unequivocally compare the relevance of these cytokines in diverse clinical settings within the perinatal period. Moreover, advances in clinical methods for bacteria detection, for example, the optimization of Bioprinted Microarray Based Interferometric Point-of-Care Device [24], may provide in the near future helpful tools to rapidly identify infections in the perinatal clinical diagnosis setting.

IL-8, also called CXCL8, is a pro-inflammatory chemokine classically secreted by monocytes, macrophages, and endothelial cells in adulthood to recruit and activate neutrophils as well as $\gamma \delta$ T cells [34]. During pregnancy, intrauterine IL-8 secretion in response to toll-like receptor stimulation is considered an upstream event eliciting preterm birth [5]. Dudley et al. [41] showed that decidual cells produced significant amounts of IL-8 among other chemokines in response to intact GBS in a strain-specific fashion. In our work, the enhanced response in preterm neonates suffering from infections underscores a role for 
IL-8 as a fetal signal to trigger labor in the presence of intrauterine infection. Intriguingly, in term and preterm human newborns, IL- 8 is released not only by innate cells but also profusely by cord blood T cells [42]. Such exacerbated IL-8 responses possibly compensate for the incapacity of the neonatal immune system to mount proper $\mathrm{TH}_{1}$ responses due to deficient IL-12 production by early life dendritic cells [42]. IL-12 deficiency is casually involved in perinatal vulnerability to infections for example by GBS [43], as administration of IL-12 to neonatal mice infected with GBS improves bacterial clearance and survival, highlighting the importance of IL-12 in resolving neonatal gram-positive sepsis [44]. From our present data, it is not possible to assert whether IL-12 release was deficiently induced in cord blood cells, and we observed comparable IL-12 levels among the three bacteria lysates studied. IL-12 can stimulate naïve T-cells to differentiate into $\mathrm{TH}_{1}$ cells, hereby enhancing the production of IFN $\gamma$ and cell-mediated immunity [40]. In our in vitro system, IFN $\gamma$ was only marginally induced in all cultures, reinforcing a limited ability of UBMC to mount $\mathrm{TH}_{1}$ responses also upon stimulation with E. faecalis, S. agalactiae, and S. aureus components.

Moreover, we could confirm our hypothesis that lysates of different gram-positive bacterial species induce distinct inflammatory responses in terms of the soluble markers investigated. These bacteria contain individual, strain-specific compositions of pathogenassociated molecular patterns (PAMPs) such as peptidoglycan monomers, lipoteichoic acids, mannose-rich glycans, lipoproteins, flagellin, and CpG motif containing DNA among others. Binding of these components to pattern recognition receptors (PRR) triggers in a co-ordinate activation of different effector cells of the innate immune system, resulting in the production of various cytokines and chemokines $[45,46]$. Herein, unique compositions of immune-modulatory components within the lysates of tested bacteria may trigger the release of the observed strain-specific profiles of cyto-/chemokines by UBMC. In our in vitro setting, we could observe that E. faecalis lysates generally elicited more moderate response than S. agalactiae and S. aureus. In fact, despite its pathogenicity, E. faecalis has been postulated as a potential probiotic [47]. The maternal E. faecalis colonization of the gastrointestinal tract in healthy newborns has been associated to protection from gut infections in the later life of the infant [48]. It has been reported that E. faecalis produces antibacterial compounds and attenuates inflammatory responses to other pathogens in vitro and in vivo, e.g., by suppressing IL-8 or by promoting IL-10 secretion [47], which together may account for the relatively moderate cytokine stimulation observed here in response to $E$. faecalis. An exception to this is MCP-1, which was prominently induced by E. faecalis lysates compared to lysates form the other bacteria. MCP-1, also called CCL2, mediates the recruitment of monocytes, activated T-cells, basophils, NK-cells, and immature dendritic cells. MCP-1 secretion by neutrophils can prevent severe sepsis stemming from oral $E$. faecalis infection [49] by modulating macrophage differentiation. Importantly, a potent MCP-1 response appears as a salient trait in response to $E$. faecalis infection, which has been referred to by in vitro and in vivo studies [50] and may potentially serve to differentiate $E$. faecalis from other neonatal infections.

Although S. agalactiae is often part of the gastrointestinal and genitourinary microbiota in immunocompetent individuals, it is also a leading cause of maternal chorioamnionitis, neonatal meningitis, and sepsis worldwide. Our results show that $S$. agalactiae induced prominent inflammatory responses in UBMC, indicating that the neonatal immunity is readily responsive to these bacteria components. Still more potent was the response of UBMC to $S$. aureus lysates, a commensal bacterium that is among the most common causes of chorioamnionitis, preterm birth, and late-onset sepsis in very-low birth weight infants [19]. Rather than stimulating MCP-1, S. agalactiae and S. aureus elicited higher MIP- $1 \alpha$ release than E. faecalis. MIP- $1 \alpha$ participates in the host response, e.g., to invading bacteria by regulating the trafficking and activation state of leukocytes such as macrophages, lymphocytes, and NK cells [51,52]. The stepwise upregulation of MIP- $1 \alpha$ first by S. agalactiae and then by $S$. aureus respectively may relate to an enhanced inflammatory profile, also mirrored in a corresponding stepwise increase of TNF $\alpha$ and the anti-inflammatory cytokine IL-10 after incubations with S. aureus lysate. IL-10 is an important regulator and suppressor 
of the pro-inflammatory cascade [53]. It is produced at the maternal-fetal interface to promote immune tolerance of the fetal allograft [53]. Also, administration of IL-10 increases the survival of neonatal mice suffering from GBS sepsis [54] due to its potential to restrict inflammation and to reduce tissue damage in the host defense [55]. Moreover, S. aureus lysates elicited the highest secretion of TNF $\alpha$, indicating robust activation of the innate immunity in these cultures [56,57]. It remains however unclear why lysates of $S$. aureus show a stronger capacity than the lysates of the other bacteria to trigger the release of most cytokines by UBMCs. Also in the case of $S$. aureus, recent research has shown that bacterial wall compounds including lipoproteins [58] but not peptidoglycans [59] are centrally required for immune responses elicited in the context of arthritis. Indeed, $S$. aureus lipoproteins potently target macrophage TLR2 to induce chemokines secretion and to either trigger septic arthritis (if lipoproteins were administered alone) or to strengthen the clearance of bacteria in the case of infection [58]. In the case of S. agalactiae among the many components proposed to play a role [60], lipoproteins are important mediators of its virulence [61]. Hence, it remains to be investigated whether the observed exacerbated effects of the $S$. aureus over the other bacteria are mediated by distinct properties of each bacteria lipoproteins and whether, in the context of perinatal infections, lipoproteins also may mediate a comparable effect to arthritis, e.g., by potentiating chemokine secretion and the resolution of infection.

Finally, with the present data, we have advanced our previous work $[26,62]$ by the laborious optimization of our in vitro model by testing multiple dosages of lysates of clinically relevant gram-positive bacteria collected in our clinic and by analyzing comparatively the evoked responses. Indeed, UBMC stimulations proved to be an efficient noninvasive method to assess neonatal immunity to unveil distinct profiles of cytokine responses in neonates. Importantly, in our settings, cytokine secretion evoked by increasing levels of bacteria lysates presented a bimodal response, with stabilization or reduction of cytokine levels in stimulations with higher concentrations of bacteria lysates. Such a bimodal response has been already reported in multiple settings [63-67]. Suppression of cytokine production in high stimulatory conditions may rely on auto/paracrine and intracellular negative feedback pathways $[63,68]$. Alternatively, high concentrations of bacterial products, such as LPS, can trigger excessive oxidative mediators with toxic effects and can reduce cell viability $[65,66]$. For these reasons, in the optimization, we decided to favor an intermediate bacterial lysate concentration, which evoked significant cytokine responses that remained below toxicity or saturation levels.

We consider that the present observations provide valuable insights in the capacity of the studied bacteria to activate and modulate the perinatal immune system and thus to contribute to a rational estimation of the importance of these pathogens in pregnancy and early life. In the present study, we prioritized screening for the cumulative secretion throughout $36 \mathrm{~h}$ of stimulation, as an indicator of the type and potency of the overall inflammatory responses evoked by the three bacteria. Within this time frame, a substantial immune activation is expected to take place, as evidenced by the rising levels of TNF $\alpha$ and IL-12. This approach is possible given that our [69,70] and other [71] previous work showed that the detected cytokines present sufficient stability for at least $36 \mathrm{~h}$ in the present culture conditions at $37^{\circ} \mathrm{C}$. The only exception to this prolonged stability may reside in $\mathrm{TNF} \alpha$ levels [70], for which, although the presented comparisons remain valid, they may not represent the full cumulative TNF $\alpha$ induction throughout the complete stimulation period. Noticeably, our study triggers interesting questions about the dynamics of the inflammatory response to different bacteria, which due to its high relevance in the context of perinatal infections and neonatal sepsis shall be investigated in upcoming studies.

Importantly, in the present work, we could confirm our in vitro findings also in the perinatal responses in vivo by reporting enhanced IL-8 secretion in preterm born infants suffering from infections, which underscores the clinical application of our observations. Our data of sex-specific differences in the secretion of chemokines, particularly of MIP$1 \beta$ at early stages of the immune response, may contribute to shedding light on as yet 
undiscovered mechanisms underlying male vulnerability to perinatal complications [37], which merits further examination. We consider that our experimental method opens new opportunities for investigations, for example, of the responses of UBMC from preterm vs. term born neonates. It also gives new possibilities for translational research, for example, by contrasting our findings with the levels of cytokines in women at risk from preterm birth and by evaluating their risk of infection-related complications after birth.

Taken together, we envision that the present research advances towards the ultimate goal of developing strategies to prevent, identify, and treat infection-triggered preterm birth and the associated complications of mothers and babies.

\section{Materials and Methods}

\subsection{Umbilical Cord Blood Source}

Informed consent was voluntary obtained either from twelve healthy mothers or from women undergoing preterm birth. Healthy participants that delivered vaginally at term were nonsmokers, were not under medical treatment, and showed no signs of infection during pregnancy. In the case of cord blood samples collected from preterm-born infants, control samples were collected from participants undergoing preterm delivery due to noninfectious conditions, such as preeclampsia including severe hypertension in pregnancy, and placenta insufficiency followed by fetal growth retardation. Additional samples collected from neonates born preterm, suspected to be due to infections, were included in the study after prospective confirmation of the presence of bacterial infections.

Following ligation of the umbilical cord, cord blood was collected immediately at birth in citrate bags, stored at $4{ }^{\circ} \mathrm{C}$ in the fridge, and processed within $12 \mathrm{~h}$ for in vitro studies (Table S1). For detection of IL-8, plasma from preterm born infants was isolated, transferred to the lab and measured using a commercial Elisa. The protocol of the study was conducted in accordance with the World Medical Association Declaration of Helsinki and approved by the Ethical Commission of the University of Regensburg, Center for Clinical Studies (Approval number 06/098, date of approval 9 August 2006, last amendment 23 January 2015).

\subsection{Isolation of Umbilical Cord Blood Mononuclear Cells (UBMC)}

The freshly citrated umbilical cord blood was diluted 1:3 with PBS. Subsequently, 25 to $30 \mathrm{~mL}$ of the diluted blood were carefully overlaid by $15 \mathrm{~mL}$ Pancoll (Lymphocyte sep. medium/Pancoll human, density $1.077 \mathrm{~g} / \mathrm{mL}$, PAN, Biotech, Aidenbach, Germany) in a $50-\mathrm{mL}$ tube. UBMC were separated by density gradient centrifugation $(800 \times g$, $30 \mathrm{~min}$ ) at room temperature (RT), harvested as a single interface layer between the Pancoll cusion and the blood plasm, and washed three times with $45 \mathrm{~mL}$ PBS. Contaminating erythroblasts were eliminated by lysis in 1-mL erythrocyte lysis buffer (BD Pharm Lyse ${ }^{\mathrm{TM}}$ Lysing Buffer, Cat. No. 555899, Becton Dickinson Biosciences Pharmingen, San José, CA, USA) for $10 \mathrm{~min}$ at RT, followed by two additional washes in $45 \mathrm{~mL}$ PBS. Cell pellets of each donor were resuspended in T-cell medium (RPMI 1640 medium, Gibco, Paisley, Scotland), supplemented with $10 \%$ heat-inactivated $\left(1 \mathrm{~h}, 56^{\circ} \mathrm{C}\right)$ human $\mathrm{AB}$ serum, and enumerated using a Neubauer counting chamber to determine the total number of cells. Total cell number was adjusted to $2 \times 10^{5}$ cells per $90 \mu \mathrm{L}$ in T-cell medium.

\subsection{Preparation of Bacterial Lysates}

Each clone of the Streptococcus, Enterococcus, and Staphylococcus strains was isolated from a vaginal swap of a 29-year-old patient suffering from PTL at the Department of Bacteriology, Institute of Clinical Microbiology and Hygiene, University Hospital Regensburg. Samples were plated on the corresponding selective media: Mueller Hinton for isolating Enterococcus and Mueller Hinton plates including 5\% blood to isolate Streptococcus and Staphylococcus. One single colony of each bacterial strain was picked and cultivated overnight in $5 \mathrm{~mL}$ Lysogeny broth (LB) media at $37{ }^{\circ} \mathrm{C}$ and shaken at $220 \mathrm{rpm}$. Subsequently, $50 \mathrm{~mL}$ LB media was inoculated with $1 \mathrm{~mL}$ of the overnight culture and incubated 
for $4.5 \mathrm{~h}$ at $37^{\circ} \mathrm{C}$ and $220 \mathrm{rpm}$. Then, each 1-L LB medium was inoculated with 7.5-10 mL bacterial suspension (depending on the growth rates of the bacterial strain) and incubated for $16 \mathrm{~h}$ at $37^{\circ} \mathrm{C}$ and $150 \mathrm{rpm}$. Each strain was harvested during logarithmic growth phase by centrifugation at $4{ }^{\circ} \mathrm{C}$ for $10 \mathrm{~min}$ and $4000 \mathrm{rpm}$. The cell pellet was resuspended in 10 to $20 \mathrm{~mL}$ PBS, and cell lysates were produced by disruption in a French Press lysis at $1.5 \mathrm{k}$ Bar and $3{ }^{\circ} \mathrm{C}$ yielding in $30 \mathrm{~mL}$ of the Streptococcus lysate at a concentration of $0.54 \mathrm{mg} / \mathrm{mL}, 30 \mathrm{~mL}$ of Enterococcus-lysate at a concentration of $0.62 \mathrm{mg} / \mathrm{mL}$, and $30 \mathrm{~mL}$ of Staphylococcus lysate at a concentration of $1.42 \mathrm{mg} / \mathrm{mL}$. After extraction, blood agar dishes were inoculated with aliquots of each lysate for $48 \mathrm{~h}$. The absence of colony-forming units served to exclude the presence of remaining living bacteria. Total protein content of the lysates was determined in a Bradford Assay (BioRad Laboratories $\mathrm{GmbH}$, Munich, Germany) and obtained lysates were aliquoted and stored at $-20^{\circ} \mathrm{C}$.

\subsection{Stimulation of UBMC with Gram-Positive Bacterial Lysates}

Freshly isolated UBMC $\left(2 \times 10^{5}\right)$ were resuspended in culture media $(10 \%$ heatinactivated human AB serum 1\% ampicillin RPMI 1640 medium) and seeded in triplicate (90 $\mu \mathrm{L}$ per well) into polypropylene plastic 96-well plates (Nunc, Roskilde, Denmark). Noteworthy, the supplementation of culture media with the antibiotic ampicillin aimed to prevent the growth of potential residual live bacteria remaining after the French press procedure. Unless otherwise indicated, cells were stimulated with 0.157 prepared lysate in $100 \mu \mathrm{L}$ final volume for $36 \mathrm{~h}$ at $37^{\circ} \mathrm{C}$ in a humidified atmosphere containing $5 \% \mathrm{CO}_{2}$. UBMC stimulated with PBS served as a negative control. Cell-free supernatants of stimulated cells were harvested by low-speed centrifugation $(300 \times g, 10 \mathrm{~min})$ and stored at $-80^{\circ} \mathrm{C}$.

\subsection{Determination of Cytokine and Chemokine Concentrations in UBMC Supernatants}

The levels of cytokines and chemokines in the UBMC supernatants were determined applying the Luminex technology (MicroBIOMix GmbH, Regensburg, Germany). All the assays for a particular cytokine were run at the same time to limit intra-assay difference. First, the Human Cytokine 5-Plex panel (LHC6003, Invitrogen/ThermoFisher, Invitrogen Corporation, Carlsbad, CA, USA) and additional kits for detection of TGF-B (LHG0121) and IL-5 (LHC0051) were employed to optimize the concentration of the lysate required. Subsequent Luminex assays were conducted using the following human singleplex beads kits (Invitrogen/ThermoFisher): IL-10 (LHC0101), IL-6 (LHC0061), IL-8 (LHC0081), IL-12 [p40/p70] (LHC0121), TNF $\alpha$ (LHC3011), IFN $\gamma$ (LHC4031), MIP-1 $\alpha$ (LHC1021) MIP-1 $\beta(L H C 1051)$, and MCP-1 (LHC1011). Experiments were performed using the Human Extracellular Protein Buffer Reagent Kit (LHB0001, Invitrogen/ThermoFisher, Invitrogen Corporation, Carlsbad, CA, USA) according to the manufacturers' protocol. The assays were performed in 96-well filter bottom plates. The beads were protected from light throughout the procedure. The lyophilized standard was reconstituted in $2 \mathrm{~mL}$ assay diluents and 1:3 serial dilutions were undertaken to generate a seven standard concentration set, while diluent alone served as a blank. The filtered plates were pre-washed with $200 \mu \mathrm{L}$ of wash solution/well for $30 \mathrm{~s}$. Wash solutions were aspirated using a vacuum manifold, and the bottom of the plate was blotted on paper towels to remove residual liquid. The concentrated bead mix was diluted 1:20 in wash solution. The bead solution was vortexed and sonicated immediately prior to adding $50 \mu \mathrm{L} /$ well. The plate was washed twice with $200 \mu \mathrm{L}$ wash solution/well as above. Incubation buffer $(50 \mu \mathrm{L})$ and each standard $(100 \mu \mathrm{L})$ were added in duplicate. Assay diluent $(50 \mu \mathrm{L})$ was added to each well followed by the addition of the sample $(50 \mu \mathrm{L})$. Given that in the optimization experiments (Figure 1) levels of IL-8, MCP-1, and MIP-1 $\beta$ exceeded the detection range of the Luminex assay in the concentration of $0.157 \mu \mathrm{g} / \mathrm{mL}$ of bacteria lysate, a 1:100 dilution of the supernatant was employed in the measure of these chemokines. The plate was covered and incubated for $2 \mathrm{~h}$ at RT on an orbital plate shaker (600 rpm). Afterwards, the liquid was removed using a vacuum manifold, and the plate was washed twice. A biotinylated detection antibody $(100 \mu \mathrm{L})$ was added and plate was covered and incubated on the shaker for $1 \mathrm{~h}$ at RT. The plate was washed twice prior to 
the addition of Streptavidin-RPE (100 $\mu \mathrm{L})$, then covered and incubated for $30 \mathrm{~min}$ at RT on the shaker. Finally, the plate was washed three times. The wash solution $(110 \mu \mathrm{L})$ was added to each well, and the plate was covered, placed on the orbital shaker and incubated for 2-3 min at RT prior to analysis. Mean fluorescence intensity (MFI) was acquired using the Luminex xMAP 100 system (Luminex Corporation, Austin, Texas, USA) Software was set to acquire data using the $70 \mu \mathrm{L}$ sample and to count 100 events per single bead set.

Cyto- and chemokine concentrations were calculated using a 4- or 5-parameter logistic fit curve generated from the 7 standards using the Liquichip Analyzer software (Liquichip ${ }^{\mathrm{TM}}$-Analyser-Software, Qiagen $\mathrm{GmbH}$, Hilden, Germany) and expressed in $\mathrm{pg} / \mathrm{mL}$ in accordance with international standards.

\subsection{Statistical Analysis}

Depending on the experimental design, statistical differences between measured values were analyzed either using nonparametric one-way ANOVA (Figure 1) or nonparametric Friedman test (Figure 2) for paired samples, followed by post hoc comparisons to detect differences between groups. $p$ values $\leq 0.05$ were considered statistically significant. Mann-Whitney $U$ test was used to compare the levels of each cytokine for each bacteria lysate between UBMC cultures derived from female and male donors (Figure 3) and IL-8 levels in cord blood from preterm born neonates (Figure 4). Statistical tests were performed using SPSS 25 (for Windows) and GraphPad Prism 8.4.3.

Supplementary Materials: The following are available online at https:/ / www.mdpi.com/1422-006 $7 / 22 / 1 / 332 / s 1$.

Author Contributions: Conceptualization: E.R. and L.D.; Methodology: E.R., L.D. and M.T.; Software, E.R. and M.E.S.; Validation: E.R., L.D. and M.E.S.; Formal analysis: E.R., L.D. and M.E.S.; Investigation: E.R.; Resources: E.R., M.T., L.D., S.H., B.S.-G., M.E.S.; Data curation: E.R.; Writingoriginal draft preparation: E.R. and M.E.S. Writing—review and editing: E.R., L.D., M.T., S.H. and M.E.S.; Visualization: E.R., M.T. and M.E.S.; Supervision: E.R., L.D., B.S.-G. and M.E.S.; Project administration: E.R. Funding acquisition: B.S.-G., M.E.S. All authors have read and agreed to the published version of the manuscript.

Funding: This research was funded by the institutional research fund of the University of Regensburg to B.S.-G and by the German Research Foundation to M.E.S. (SO1413/2-1; SO1413/3-1).

Institutional Review Board Statement: The study was conducted according to the guidelines of the Declaration of Helsinki, and approved by the Ethics Committee of the University of Regensburg, Center for Clinical Studies (Approval number 06/098, date of approval 09/08/2006, last amendment 23/01/2015).

Informed Consent Statement: Informed consent was obtained from all pregnant women involved in the study.

Data Availability Statement: The data presented in this study are completely available in the present manuscript and supplementary figures.

Acknowledgments: The authors express their gratitude to Ellen Wiesler and Maren Werner for excellent technical assistance, Elke Saha for her skilled library support, Florian Zeman and Isabel Hartwig for their assistance in performing the statistical analysis, and Klaus Voelcker for his contribution to the figures. Finally, we want to extend our thanks to all the study participants, notable pregnant women who made this study possible.

Conflicts of Interest: The authors declare no conflict of interest. M.T. is currently employed at MicroBIOMIX and L.D. at Lophius Biosciences. MicroBIOMIX and Lophius Biosciences had no role in study design, data collection and analysis, decision to publish, or preparation of the manuscript. There are no patents, products in development or marketed products associated with this research to declare. 


\section{References}

1. Goldenberg, R.L. The management of preterm labor. Obstet. Gynecol. 2002, 100, 1020-1037. [PubMed]

2. Chawanpaiboon, S.; Vogel, J.P.; Moller, A.-B.; Lumbiganon, P.; Petzold, M.; Hogan, D.; Landoulsi, S.; Jampathong, N.; Kongwattanakul, K.; Laopaiboon, M.; et al. Global, regional, and national estimates of levels of preterm birth in 2014: A systematic review and modelling analysis. Lancet Glob. Health 2019, 7, e37-e46. [CrossRef]

3. Martin, J.A.; Hamilton, B.E.; Osterman, M.J.K.; Driscoll, A.K.; Drake, P. Births: Final Data for 2016. Natl. Vital. Stat. Rep. 2018, 67, 1-55. [PubMed]

4. Romero, R.; Espinoza, J.; Gonçalves, L.F.; Kusanovic, J.P.; Friel, L.; Hassan, S. The Role of Inflammation and Infection in Preterm Birth. Semin. Reprod. Med. 2007, 25, 21-39. [CrossRef] [PubMed]

5. Romero, R.; Dey, S.K.; Fisher, S.J. Preterm labor: One syndrome, many causes. Science 2014, 345, 760-765. [CrossRef]

6. Frascoli, M.; Coniglio, L.; Witt, R.; Jeanty, C.; Fleck-Derderian, S.; Myers, D.E.; Lee, T.-H.; Keating, S.M.; Busch, M.P.; Norris, P.J.; et al. Alloreactive fetal T cells promote uterine contractility in preterm labor via IFN- $\gamma$ and TNF- $\alpha$. Sci. Transl. Med. 2018, 10, eaan2263. [CrossRef]

7. Montalbano, A.P.; Hawgood, S.; Mendelson, C.R. Mice Deficient in Surfactant Protein A (SP-A) and SP-D or in TLR2 Manifest Delayed Parturition and Decreased Expression of Inflammatory and Contractile Genes. Endocrinology 2013, 154, $483-498$. [CrossRef]

8. Muhammad, Z.; Ahmed, A.; Hayat, U.; Wazir, M.S.; Rafiyatullah; Waqas, H. Neonatal sepsis: Causative bacteria and their resistance to antibiotics. J. Ayub. Med. Coll. Abbottabad JAMC 2012, 22, 33-36.

9. Weinstein, R.A.; Gaynes, R.; Edwards, J.R.; System, N.N.I.S. Overview of Nosocomial Infections Caused by Gram-Negative Bacilli. Clin. Infect. Dis. 2005, 41, 848-854. [CrossRef]

10. Chen, C.; Song, X.; Chunwei, Z.; Zhong, H.; Dai, J.; Lan, Z.; Li, F.; Yu, X.; Feng, Q.; Wang, Z.; et al. The microbiota continuum along the female reproductive tract and its relation to uterine-related diseases. Nat. Commun. 2017, 8, 1-11. [CrossRef]

11. De Gier, B.; Van Kassel, M.N.; Sanders, E.A.M.; Van De Beek, D.; Hahné, S.J.M.; Van Der Ende, A.; Bijlsma, M.W. Disease burden of neonatal invasive Group B Streptococcus infection in the Netherlands. PLoS ONE 2019, 14, e0216749. [CrossRef] [PubMed]

12. Christie, C.; Hammond, J.; Reising, S.; Evans-Patterson, J. Clinical and molecular epidemiology of enterococcal bacteremia in a pediatric teaching hospital. J. Pediatr. 1994, 125, 392-399. [CrossRef]

13. Kaufman, D.A.; Fairchild, K.D. Clinical Microbiology of Bacterial and Fungal Sepsis in Very-Low-Birth-Weight Infants. Clin Microbiol. Rev. 2004, 17, 638-680. [CrossRef] [PubMed]

14. Bianconi, S.; Gudavalli, M.; Sutija, V.G.; Lopez, A.L.; Barillas-Arias, L.; Ron, N. Ranitidine and late-onset sepsis in the neonatal intensive care unit. J. Perinat. Med. 2007, 35, 147-150. [CrossRef] [PubMed]

15. Stoll, B.J.; Hansen, N.I.; Sánchez, P.J.; Faix, R.G.; Poindexter, B.B.; Van Meurs, K.P.; Bizzarro, M.J.; Goldberg, R.N.; Frantz, I.D.; Hale, E.C.; et al. Early Onset Neonatal Sepsis: The Burden of Group B Streptococcal and E. coli Disease Continues. Pediatry 2011, 127, 817-826. [CrossRef] [PubMed]

16. Maisey, H.C.; Doran, K.S.; Nizet, V. Recent advances in understanding the molecular basis of group BStreptococcusvirulence. Expert Rev. Mol. Med. 2008, 10, e27. [CrossRef]

17. Doster, R.S.; Kirk, L.A.; Tetz, L.M.; Rogers, L.M.; Aronoff, D.M.; Gaddy, J.A. Staphylococcus aureus Infection of Human Gestational Membranes Induces Bacterial Biofilm Formation and Host Production of Cytokines. J. Infect. Dis. 2017, 215, 653-657. [CrossRef]

18. Jimenez-Truque, N.; Tedeschi, S.; Saye, E.J.; McKenna, B.D.; Langdon, W.; Wright, J.P.; Alsentzer, A.; Arnold, S.; Saville, B.R.; Wang, W.; et al. Relationship Between Maternal and Neonatal Staphylococcus aureus Colonization. Pediatry 2012, 129, e1252-e1259. [CrossRef]

19. Geng, W.; Qi, Y.; Li, W.; McConville, T.H.; Hill-Ricciuti, A.; Grohs, E.C.; Saiman, L.; Uhlemann, A.-C. Epidemiology of Staphylococcus aureus in neonates on admission to a Chinese neonatal intensive care unit. PLoS ONE 2020, 15, e0211845. [CrossRef]

20. Romero, R.; Chaiworapongsa, T.; Espinoza, J. Micronutrients and Intrauterine Infection, Preterm Birth and the Fetal Inflammatory Response Syndrome. J. Nutr. 2003, 133, 1668S-1673S. [CrossRef]

21. Agrawal, V.; Hirsch, E. Intrauterine infection and preterm labor. Semin. Fetal Neonatal Med. 2012, 17, 12-19. [CrossRef] [PubMed]

22. Shane, A.L.; Sánchez, P.J.; Stoll, B.J. Neonatal sepsis. Lancet 2017, 390, 1770-1780. [CrossRef]

23. Stefanovic, I.M. Neonatal sepsis. Biochem. Med. 2011, 276-281. [CrossRef] [PubMed]

24. Dey, P.; Fabri-Faja, N.; Calvo-Lozano, O.; Terborg, R.A.; Belushkin, A.; Yesilkoy, F.; Fàbrega, A.; Ruiz-Rodriguez, J.C.; Ferrer, R.; González-López, J.J.; et al. Label-free Bacteria Quantification in Blood Plasma by a Bioprinted Microarray Based Interferometric Point-of-Care Device. ACS Sens. 2019, 4, 52-60. [CrossRef] [PubMed]

25. Chen, S.; Popovich, J.; Zhang, W.; Ganser, C.; Haydel, S.E.; Seo, D.-K. Superior ion release properties and antibacterial efficacy of nanostructured zeolites ion-exchanged with zinc, copper, and iron. RSC Adv. 2018, 8, 37949-37957. [CrossRef]

26. Reuschel, E.; Toelge, M.; Entleutner, K.; Deml, L.; Seelbach-Goebel, B. Cytokine profiles of umbilical cord blood mononuclear cells upon in vitro stimulation with lipopolysaccharides of different vaginal gram-negative bacteria. PLoS ONE 2019, 14, e0222465. [CrossRef]

27. Kim, C.J.; Romero, R.; Chaemsaithong, P.; Chaiyasit, N.; Yoon, B.H.; Kim, Y.M. Acute chorioamnionitis and funisitis: Definition, pathologic features, and clinical significance. Am. J. Obstet. Gynecol. 2015, 213, S29-S52. [CrossRef] 
28. Zeitlin, J.; Saurel-Cubizolles, M.-J.; De Mouzon, J.; Rivera, L.; Ancel, P.; Blondel, B.; Kaminski, M. Fetal sex and preterm birth: Are males at greater risk? Hum. Reprod. 2002, 17, 2762-2768. [CrossRef]

29. Cortese, F.; Scicchitano, P.; Gesualdo, M.; Filaninno, A.; De Giorgi, E.; Schettini, F.; Laforgia, N.; Ciccone, M.M. Early and Late Infections in Newborns: Where Do We Stand? A Review. Pediatr. Neonatol. 2016, 57, 265-273. [CrossRef]

30. Scotland, R.S.; Stables, M.J.; Madalli, S.; Watson, P.; Gilroy, D.W. Sex differences in resident immune cell phenotype underlie more efficient acute inflammatory responses in female mice. Blood 2011, 118, 5918-5927. [CrossRef]

31. Le Rouzic, V.; Corona, J.; Zhou, H. Postnatal Development of Hepatic Innate Immune Response. Inflammation 2010, 34, 576-584. [CrossRef]

32. Madalli, S.; Beyrau, M.; Whiteford, J.R.; Duchêne, J.; Nandhra, I.S.A.; Patel, N.S.; Motwani, M.P.; Gilroy, D.W.; Thiemermann, C.; Nourshargh, S.; et al. Sex-specific regulation of chemokine Cxcl5/6 controls neutrophil recruitment and tissue injury in acute inflammatory states. Biol. Sex Differ. 2015, 6, 27. [CrossRef] [PubMed]

33. Marriott, I.; Huet-Hudson, Y.M. Sexual Dimorphism in Innate Immune Responses to Infectious Organisms. Immunol. Res. 2006, 34, 177-192. [CrossRef]

34. Speirs, I.C.; Tronson, N.C. Sex differences in hippocampal cytokines after systemic immune challenge. Neuroscience 2018. [CrossRef]

35. Erickson, M.E.; Liang, W.S.; Fernandez, E.G.; Bullock, K.M.; Thysell, J.A.; Banks, W.A. Genetics and sex influence peripheral and central innate immune responses and blood-brain barrier integrity. PLoS ONE 2018, 13, e0205769. [CrossRef] [PubMed]

36. Bystry, R.S.; Aluvihare, V.R.; Welch, K.A.; Kallikourdis, M.; Betz, A.G. B cells and professional APCs recruit regulatory T cells via CCL4. Nat. Immunol. 2001, 2, 1126-1132. [CrossRef] [PubMed]

37. O'Driscoll, D.N.; McGovern, M.; Greene, C.M.; Molloy, E.J. Gender disparities in preterm neonatal outcomes. Acta Paediatr. 2018, 107, 1494-1499. [CrossRef]

38. Zhou, M.; Cheng, S.; Yu, J.; Lu, Q. Interleukin-8 for Diagnosis of Neonatal Sepsis: A Meta-Analysis. PLoS ONE 2015, 10, e0127170. [CrossRef]

39. Boskabadi, H.; Zakerihamidi, M. Evaluate the diagnosis of neonatal sepsis by measuring interleukins: A systematic review. Pediatr. Neonatol. 2018, 59, 329-338. [CrossRef]

40. Sacks, G.P.; Redman, C.W.G.; Sargent, I.L. Monocytes are primed to produce the Th1 type cytokine IL-12 in normal human pregnancy: An intracellular flow cytometric analysis of peripheral blood mononuclear cells. Clin. Exp. Immunol. 2003, 131, 490-497. [CrossRef]

41. Dudley, N.J.; Edwin, S.S.; Van Wagoner, J.; Augustine, N.H.; Hill, H.R.; Mitchell, M.D.; Van Wagoner, J. Regulation of decidual cell chemokine production by group B streptococci and purified bacterial cell wall components. Am. J. Obstet. Gynecol. 1997, 177, 666-672. [CrossRef]

42. Gibbons, D.; Fleming, P.; Virasami, A.; Michel, M.-L.; Sebire, N.J.; Costeloe, K.; Carr, R.; Klein, N.; Hayday, A. Interleukin-8 (CXCL8) production is a signatory T cell effector function of human newborn infants. Nat. Med. 2014, 20, 1206-1210. [CrossRef] [PubMed]

43. Hansen-Pupp, I.; Harling, S.; Berg, A.-C.; Cilio, C.; Hellström-Westas, L.; Ley, D.; Hellstr, L. Circulating Interferon-gamma and White Matter Brain Damage in Preterm Infants. Pediatr. Res. 2005, 58, 946-952. [CrossRef]

44. Mancuso, G.; Cusumano, V.; Genovese, F.; Gambuzza, M.; Beninati, C.; Teti, G. Role of interleukin 12 in experimental neonatal sepsis caused by group B streptococci. Infect. Immun. 1997, 65, 3731-3735. [CrossRef]

45. Fournier, B.; Philpott, D.J. Recognition of Staphylococcus aureus by the Innate Immune System. Clin. Microbiol. Rev. 2005, 18, 521-540. [CrossRef]

46. Kumar, A.; Kumar, P.; Basu, S. Enterococcus fecalis Sepsis and Leukemoid Reaction. J. Pediatr. Hematol. 2015, 37, e419-e420. [CrossRef]

47. Araújo, T.F.; Ferreira, C.L.D.L.F. The genus Enterococcus as probiotic: Safety concerns. Braz. Arch. Biol. Technol. 2013, 56, 457-466. [CrossRef]

48. Bhagwat, A.; Annapure, U.S. Maternal-neonatal transmission of Enterococcus strains during delivery. Beni-Suef Univ. J. Basic Appl. Sci. 2019, 8, 1-9. [CrossRef]

49. Shigematsu, K.; Asai, A.; Kobayashi, M.; Herndon, D.N.; Suzuki, F. Enterococcus faecalis translocation in mice with severe burn injury: A pathogenic role of CCL2 and alternatively activated macrophages (M2aM $\phi$ and M2cM $\phi)$. J. Leukoc. Biol. 2009, 86, 999-1005. [CrossRef]

50. Xu, Z.; Tong, Z.; Neelakantan, P.; Cai, Y.; Wei, X. Enterococcus faecalis immunoregulates osteoclastogenesis of macrophages. Exp. Cell Res. 2018, 362, 152-158. [CrossRef]

51. Wolpe, S.D.; Davatelis, G.; Sherry, B.; Beutler, B.; Hesse, D.G.; Nguyen, H.T.; Moldawer, L.L.; Nathan, C.F.; Lowry, S.F.; Cerami, A. Macrophages secrete a novel heparin-binding protein with inflammatory and neutrophil chemokinetic properties. J. Exp. Med. 1988, 167, 570-581. [CrossRef] [PubMed]

52. Hieshima, K.; Imai, T.; Baba, M.; Shoudai, K.; Ishizuka, K.; Nakagawa, T.; Tsuruta, J.; Takeya, M.; Sakaki, Y.; Takatsuki, K.; et al. A novel human CC chemokine PARC that is most homologous to macrophage-inflammatory protein-1 alpha/LD78 alpha and chemotactic for T lymphocytes, but not for monocytes. J. Immunol. 1997, 159, 1140-1149. [PubMed]

53. Peltier, M.R. Immunology of term and preterm labor. Reprod. Biol. Endocrinol. 2003, 1, 122. [CrossRef] 
54. Cusumano, V.; Genovese, F.; Mancuso, G.; Carbone, M.; Fera, M.T.; Teti, G. Interleukin-10 protects neonatal mice from lethal group B streptococcal infection. Infect. Immun. 1996, 64, 2850-2852. [CrossRef]

55. Ouyang, W.; Rutz, S.; Crellin, N.K.; Valdez, P.; Hymowitz, S.G. Regulation and Functions of the IL-10 Family of Cytokines in Inflammation and Disease. Annu. Rev. Immunol. 2011, 29, 71-109. [CrossRef]

56. Flynn, J.L.; Goldstein, M.M.; Chan, J.; Triebold, K.J.; Pfeffer, K.; Lowenstein, C.J.; Schrelber, R.; Mak, T.W.; Bloom, B.R. Tumor necrosis factor- $\alpha$ is required in the protective immune response against mycobacterium tuberculosis in mice. Immunity 1995, 2, 561-572. [CrossRef]

57. Echtenacher, B. Treatment of experimental sepsis-induced immunoparalysis with TNF. Immunobiology 2003, 208, 381-389. [CrossRef]

58. Mohammad, M.; Nguyen, M.; Engdahl, C.; Na, M.; Jarneborn, A.; Hu, Z.; Karlsson-Bengtsson, A.; Pullerits, R.; Ali, A.; Götz, F.; et al. The YIN and YANG of lipoproteins in developing and preventing infectious arthritis by Staphylococcus aureus. PLOS Pathog. 2019, 15, e1007877. [CrossRef]

59. Ali, A.; Zhu, X.; Kwiecinski, J.; Gjertsson, I.; Lindholm, C.; Iwakura, Y.; Wang, X.; Lycke, N.; Josefsson, E.; Pullerits, R.; et al. Antibiotic-KilledStaphylococcus aureusInduces Destructive Arthritis in Mice. Arthritis Rheumatol. 2014, 67, 107-116. [CrossRef]

60. Herbert, A.M.; Beveridge, C.J.; Saunders, N.J. Bacterial virulence factors in neonatal sepsis: Group B streptococcus. Curr. Opin. Infect. Dis. 2004, 17, 225-229. [CrossRef]

61. Bray, B.A.; Sutcliffe, I.C.; Harrington, D.J. Impact of lgt mutation on lipoprotein biosynthesis and in vitro phenotypes of Streptococcus agalactiae. Microbiology 2009, 155, 1451-1458. [CrossRef] [PubMed]

62. Ernst, W.; Kusi, E.; Malfertheiner, S.F.; Reuschel, E.; Deml, L.; Seelbach-Göbel, B. The effect of Indomethacin and Betamethasone on the cytokine response of human neonatal mononuclear cells to gram-positive bacteria. Cytokine 2015, 73, 91-100. [CrossRef] [PubMed]

63. Gottschalk, A.R.; Dorrington, M.G.; Dutta, B.; Krauss, K.S.; Martins, A.J.; Uderhardt, S.; Chan, W.; Tsang, J.S.; Torabi-Parizi, P.; Fraser, I.D.; et al. IFN-mediated negative feedback supports bacteria class-specific macrophage inflammatory responses. eLife 2019, 8. [CrossRef] [PubMed]

64. Helwig, U.; Lammers, K.M.; Rizzello, F.; Brigidi, P.; Rohleder, V.; Caramelli, E.; Gionchetti, P.; Schrezenmeir, J.; Foelsch, U.R.; Schreiber, S.; et al. Lactobacilli, bifidobacteriaandE. colinissle induce pro- and anti-inflammatory cytokines in peripheral blood mononuclear cells. World J. Gastroenterol. 2006, 12, 5978-5986. [CrossRef] [PubMed]

65. Memedovski, Z.; Czerwonka, E.; Han, J.; Mayer, J.; Luce, M.; Klemm, L.C.; Hall, M.L.; Mayer, A.M. Classical and Alternative Activation of Rat Microglia Treated with Ultrapure Porphyromonas gingivalis Lipopolysaccharide In Vitro. Toxins 2020, 12, 333. [CrossRef]

66. Mayer, A.M.; Murphy, J.; Macadam, D.; Osterbauer, C.; Baseer, I.; Hall, M.L.; Feher, D.; Williams, P. Classical and Alternative Activation of CyanobacteriumOscillatoriasp. Lipopolysaccharide-Treated Rat Microgliain vitro. Toxicol. Sci. 2015, 149, 484-495. [CrossRef]

67. Meyer, F.; Wilson, K.T.; James, S.P. Modulation of Innate Cytokine Responses by Products of Helicobacter pylori. Infect. Immun. 2000, 68, 6265-6272. [CrossRef]

68. Koch, L.; Frommhold, D.; Buschmann, K.; Kuss, N.; Poeschl, J.; Ruef, P. LPS- and LTA-Induced Expression of IL-6 and TNF- $\alpha$ in Neonatal and Adult Blood: Role of MAPKs and NF-кB. Mediat. Inflamm. 2014, 2014, 1-8. [CrossRef]

69. Kranzer, K.; Eckhardt, A.; Aigner, M.; Knoll, G.; Deml, L.; Speth, C.; Lehn, N.; Rehli, M.; Schneider-Brachert, W. Induction of Maturation and Cytokine Release of Human Dendritic Cells by Helicobacter pylori. Infect. Immun. 2004, 72, 4552-4560. [CrossRef]

70. Deml, L.; Aigner, M.; Decker, J.; Eckhardt, A.; Schütz, C.; Mittl, P.R.E.; Barabas, S.; Denk, S.; Knoll, G.; Lehn, N.; et al. Characterization of the Helicobacter pylori Cysteine-Rich Protein A as a T-Helper Cell Type 1 Polarizing Agent. Infect. Immun. 2005, 73, 4732-4742. [CrossRef]

71. Simpson, S.; Kaislasuo, J.; Guller, S.; Pal, L. Thermal stability of cytokines: A review. Cytokine 2020, 125, 154829. [CrossRef] [PubMed] 